\title{
Article \\ Exploitation of Enzymes for the Production of Biofuels: Electrochemical Determination of Kinetic Parameters of LPMOs
}

\author{
Dimitrios Zouraris $^{1}$, Anthi Karnaouri ${ }^{2} \mathbb{D}$, Raphaela Xydou ${ }^{1}$, Evangelos Topakas ${ }^{2}$ (D) and Antonis Karantonis ${ }^{1, *}$ \\ 1 Laboratory of Physical Chemistry and Applied Electrochemistry, School of Chemical Engineering, National \\ Technical University of Athens, Zografou, 15780 Athens, Greece; dimzouraris@mail.ntua.gr (D.Z.); \\ ch15611@mail.ntua.gr (R.X.) \\ 2 Biotechnology Laboratory, School of Chemical Engineering, National Technical University of Athens, \\ Zografou, 15780 Athens, Greece; akarnaouri@chemeng.ntua.gr (A.K.); vtopakas@chemeng.ntua.gr (E.T.) \\ * Correspondence: antkar@central.ntua.gr
}

Citation: Zouraris, D.; Karnaouri, A.; Xydou, R.; Topakas, E.; Karantonis, A. Exploitation of Enzymes for the Production of Biofuels:

Electrochemical Determination of Kinetic Parameters of LPMOs. Appl. Sci. 2021, 11, 4715

https://doi.org/10.3390/app11114715

Received: 23 April 2021

Accepted: 18 May 2021

Published: 21 May 2021

Publisher's Note: MDPI stays neutral with regard to jurisdictional claims in published maps and institutional affiliations.

Copyright: () 2021 by the authors. Licensee MDPI, Basel, Switzerland This article is an open access article distributed under the terms and conditions of the Creative Commons Attribution (CC BY) license (https:// creativecommons.org/licenses/by/ $4.0 /)$
Abstract: Lytic polysaccharide monooxygenases (LPMOs) consist of a class of enzymes that boost the release of oxidised products from plant biomass, in an approach that is more eco-friendly than the traditional ones, employing harsh chemicals. Since LPMOs are redox enzymes, they could possibly be exploited by immobilisation on electrode surfaces. Such an approach requires knowledge of kinetic and thermodynamic information for the interaction of the enzyme with the electrode surface. In this work, a novel methodology is applied for the determination of such parameters for an LPMO from the filamentous fungus Thermothelomyces thermophila, $\mathrm{MtLPMO} 9 \mathrm{H}$.

Keywords: LPMO; Fourier Transform ac Voltammetry (FTacV); cyclic voltammetry; Direct Electron Transfer (DET)

\section{Introduction}

The exploitation of lignocellulosic biomass, such as wood and agricultural residues, towards the production of fermentable sugars for the production of second-generation biofuels in an environmentally friendly way, requires of enzymatic degradation. This step has low energy requirements, selectivity, mild processing environment and no need of harsh chemicals, in contrast to classical chemical methods, and it is catalyzed by a combination of hydrolytic and oxidative enzymes [1,2]. Regarding the oxidation reactions, performing these steps in an electrochemical reactor, i.e., electroenzymatic synthesis of sugars, is a promising approach for the production of such chemicals. In principle, when electrolysis is combined with enzyme reactions, a redox enzyme is maintained in its active state through an electrode process. This can be achieved by oxidation of or a reduction in a cofactor or a mediator on the electrode surface, or by direct electron transfer to the enzyme. Therefore, applying enzyme immobilization onto the electrode and combining bioelectrocatalysis with traditional enzymatic hydrolysis offer perspectives for developing novel processes for the production of biofuels and other value-added materials from lignocellulose.

Lytic polysaccharide monooxygenases (LPMOs) are copper-dependent enzymes that have the capacity to cleave polysaccharides via an oxidative mechanism [3]. They are classified as Auxiliary Activities (AAs) in the Carbohydrate Active enZyme database (CAZy). More specifically, they are divided into seven families (AA9-11 and AA13-16) based on their sequence similarities, with the majority of those that are studied thoroughly belonging to the AA9 and AA10 families [4]. LPMOs act synergistically with other biomassdegrading enzymes and significantly boost the hydrolytic performance of cellulase and hemicellulase cocktails, primarily by improving the accessibility of the enzymes to the substrate $[5,6]$.

Until recently, the main theory regarding the mechanism of action of LPMOs involved the introduction of a single oxygen atom from molecular oxygen into the substrate, while 
taking electrons from an external electron donor for their action [7]. More recently, Bissaro et al., while examining an LPMO belonging to the AA10 family, supported the idea that the chemically relevant co-substrate of LPMO catalyzed oxidation is $\mathrm{H}_{2} \mathrm{O}_{2}$ [8]. Regardless of the mechanism of the oxidative cleavage of the polysaccharidic substrate, in both cases, the reaction is initiated when the active center of the enzyme takes an electron from an external electron donor. The nature of the donors used in laboratory experimental setups include ascorbic acid, cysteine and reduced glutathione, but also a wide range of plant-derived phenols $[9,10]$, lignin compounds [11] and photocatalytic and enzymatic systems [12]. The reported mechanisms for the initial reduction in LPMOs do not implicate any chemical steps other than a one-step, one-electron reaction.

One interesting point regarding these enzymes, which could possibly be an advantage for their electrochemical exploitation, is that their copper-containing active center is not "buried" inside their structure but can be found on a solvent-exposed, flat surface [13]. This could facilitate their use as electrode coatings, by directly providing them with electrons from an electrode surface, while immobilized on the electrode surface. Other than their study, this characteristic could lead to the exploitation of the bioelectrocatalytic action of LPMOs towards the production of oxidised products (oligosaccharides and glucans) from biomass, in concert with hydrolytic enzymes, in the absence of any external reducing agent. This means that by providing electrons directly from an electrode surface to an immobilised LPMO, the enzyme could be utilised in bioconversions through bioelectrocatalysis focusing on product life cycles. The developed bioconversions will be carried out in predominantly aqueous media using enzymes, and therefore be characterised by a limited use of toxic reagents or solvents, requiring only an ambient temperature, in the absence of any reducing agent [14].

In order to test if the above task is feasible, a parameter that should be mentioned is the standard electron transfer rate constant $\left(k^{0}\right)$ between the immobilized electrode and the enzyme. This electron transfer rate should be rather fast, so that the electrocatalytic current measured represents the rate of substrate turnover at the enzyme active site [15]. Among the electroanalytical methods, a technique that is very promising for the study of immobilised LPMOs is that of large amplitude fast Fourier transform alternating current voltammetry (FTacV), with which one can study both free and immobilised species, eliminating capacitance currents, a problem common in immobilised-on-electrode species [16-19]. In the past, this technique has been employed for the determination of the formal potential of immobilised LPMOs [20], as well as for the study of the direct electron transfer of multi-copper laccase like oxidases [6] and the interaction with epinephrine as a substrate [21]. Recently, a methodology for the extraction of the transfer coefficient $a$ and the $k^{0}$ for immobilised species has been proposed, but has yet to be applied experimentally [17]. In this work, this particular methology shall be employed for the extraction of the $k^{0}$ an LPMO from the filamentous fungus Thermothelomyces thermophila, $M t \mathrm{LPMO} 9 \mathrm{H}$, and the calulated value of $k^{0}$ shall be verified by numerical simulation. To our knowledge, $k^{0}$ values for the interaction of an immobilized LPMO with an electrode surface is reported for the first time.

\section{Materials and Methods}

Voltammetric experiments were performed in a single-compartment three-electrode cell consisting of a working electrode, a Pt wire as a counter electrode, and a $\mathrm{Ag} \mid \mathrm{AgCl}, \mathrm{KCl}$ sat. reference electrode ( $+0.197 \mathrm{~V}$ vs. NHE). The aqueous solutions of about $5 \mathrm{~mL}$ consisted of $0.5 \mathrm{M}$ acetate buffer ( $\mathrm{pH}$ 6) as a supporting electrolyte.

The working electrode consisted of a cobalt functionalised multi-walled carbon nanotubes modified glassy carbon (GC) electrode, of $3 \mathrm{~mm}$ diameter. The immobilisation matrix was prepared as follows: A total of $1 \mathrm{~g}$ of commercial functionalised multi-wall carbon nanotubes (MWCNTs) (Hongwu Material, item No: C933-MC, Guangzhou, China) were added in a $150 \mathrm{~mL}$ solution with $20 \% \mathrm{v} / \mathrm{v}$. The suspension was stirred for $20 \mathrm{~min}$ at $120^{\circ} \mathrm{C}$ for further functionalization, until the liquid phase was evaporated. The solution 
was left to dry overnight at $90^{\circ} \mathrm{C}$ until dry powder was collected. The powder was washed, then centrifuged 5 times with deionised water until the supernatant had a $\mathrm{pH}$ value of $\simeq 7.0$. This step ensured the removal of acetic acid excess. The obtained functionalised commercial MWCNTs (f-MWCNT) were left to dry at $90^{\circ} \mathrm{C}$. Subsequently, the f-MWCNTs were mixed with $150 \mathrm{~mL}$ deionised water and $0.4227 \mathrm{~g}$ of $\left(\mathrm{CH}_{3} \mathrm{COO}\right)_{2} \mathrm{Co} \cdot 4 \mathrm{H}_{2} \mathrm{O}$ (MERCK) leading to a loading 10 atom $\%$ Co on f-MWCNTs, which was then subjected to sonication at a low frequency $(20 \mathrm{kHz})$ using a Hielscher (UIP500hd) sonicator (probe tip diameter of $22 \mathrm{~mm}$ ) for $1 \mathrm{~h}$. The solution was further left to dry and centrifuged (as described above) for the collection of the final product. The cobalt-functionalised MWCNTs (Co-f-MWCNTs) were stored in a desiccator at room temperature.

For the immobilisation of the enzyme on the electrode, the following procedure was followed: A total of $0.005 \mathrm{~g}$ of Co-f-MWCNTs were suspended in $500 \mu \mathrm{L}$ of Nafion ${ }^{\mathrm{TM}}$ perfluorinated resin solution (concentration $5 \mathrm{wt} \%$ in lower aliphatic alcohols and water, Aldrich). Then, $8 \mu \mathrm{L}$ of the enzyme were mixed with $2 \mu \mathrm{L}$ of Co-f-MWCNTs suspension. Finally, $2 \mu \mathrm{L}$ of the resulting mix were left to dry on the GC electrode surface.

$M t \mathrm{LPMO9H}$ was produced and purified to homogeneity as previously described [22]. After the purification the enzyme was divided in aliquots of $500 \mu \mathrm{L}$, and stored at $-15^{\circ} \mathrm{C}$ until use. Each aliquot was stored for a maximum time of 2 days at $4{ }^{\circ} \mathrm{C}$ after its first use. The concentration of the purified enzyme was about $5.5 \mathrm{mg} / \mathrm{mL}$, identified by the method introduced by Lowry et al. [23].

\section{Results}

\subsection{Cyclic Voltammetry}

As a first step in the examination of the interaction of the immobilised $M t \mathrm{LPMO} H \mathrm{H}$ with the electrode surface via direct electron transfer, cyclic voltammetry was performed. $M t$ LPMO9H was immobilised on a Co-f-MWCNTs modified GC electrode and the potential was scanned between 0.6 and $-0.1 \mathrm{~V}$ at a scan rate of $0.1 \mathrm{~V} \mathrm{~s}^{-1}$. The voltammogram is presented in Figure 1 (black curve). Two rather faint peaks appear, one during the cathodic scan appearing at $0.252 \mathrm{~V}$ and one during the anodic scan at $0.281 \mathrm{~V}$. Capacitance currents are evident in this voltammogram. The peak separation is estimated at $0.029 \mathrm{~V}$, indicating a quasi-reversible reaction. The cyclic voltammetry of the Co-f-MWCNTs modified GC electrode in the absence of the enzyme is also present in Figure 1 (red curve). In this case, no redox peaks are detected, indicating that the redox peaks can indeed be attributed to the redox reaction of the enzyme and not any interference of the matrix.

In order to extract the kinetic constant $k^{0}$ and the transfer coefficient $a$ from a cyclic voltammogram, assuming Butler-Volmer kinetics [24], one would take advantage of the correlation of the anodic and cathodic peak shift by varying the scan rate. However, these equations do not take the capacitance current and how it might affect the dependence of the peak shift into account. Moreover, at the higher scan rates which would be necessary in such a case, the capacitance would be more dominant, thus rendering the analysis even more difficult. One option would be to subtract the capacitance current from the total current in order to have only the Faradaic component and base the analysis on that alone. However, uncertainty rises for the precision of this approach in cases of non-ideal capacitance. The same uncertainty arises in case one would attempt to extract other magnitudes from the cyclic voltammogram, such as the surface coverage of the enzyme immobilised on the electrode surface. 


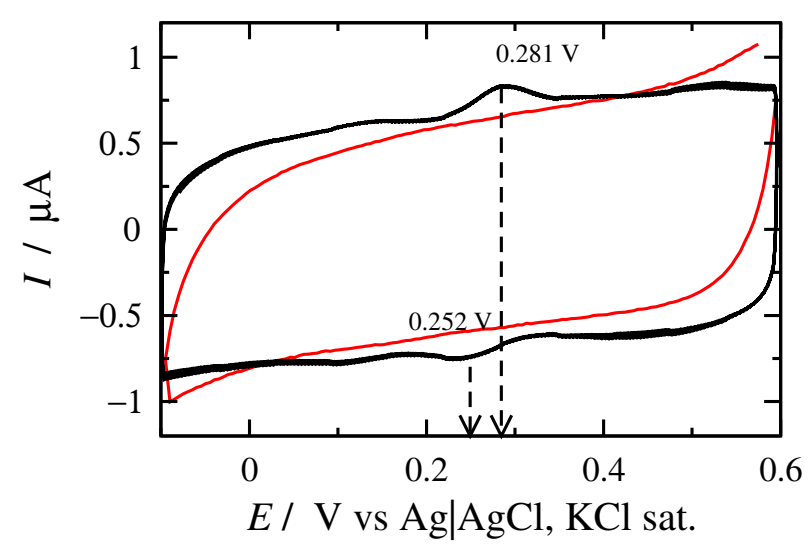

Figure 1. Experimental results: Cyclic voltammetry of MtLPMO9H immobilised on a Co-f-MWCNTs modified GC electrode (black) and Co-f-MWCNTs modified GC electrode without enzyme (red) at $25^{\circ} \mathrm{C}$. Experimental conditions: acetate buffer $500 \mathrm{mM}(\mathrm{pH} 6)$ and $v=0.1 \mathrm{~V} \mathrm{~s}^{-1}$.

Nonetheless, an interesting first approach to making an estimation of the value of the $k^{0}$ would be to solve the equations for the immobilised species numerically in the case of cyclic voltammetry for different standard electron transfer kinetic constants. In order to do so, the problem has to be formulated, by considering an electrochemical reaction having formal electrode potential $E^{0 \prime}$, where both oxidised $\left(E_{O x}\right)$ and reduced $\left(E_{R e d}\right)$ form of the enzyme are immobilised on the electrode surface

$$
\mathrm{E}_{\mathrm{Ox}}+\mathrm{e} \underset{k_{\mathrm{a}}}{\stackrel{k_{\mathrm{c}}}{\rightleftharpoons}} \mathrm{E}_{\text {Red }}
$$

where $k_{\mathrm{c}}$ the cathodic kinetic constant and $k_{\mathrm{a}}$ the anodic one. The units for both kinetic constants are $1 / \mathrm{s}$. Let us denote as $\Gamma^{0}$ the initial surface concentration of $\mathrm{E}_{\mathrm{Ox}}$ species and assume a Butler-Volmer law for the rate constants

$$
\begin{aligned}
& k_{\mathrm{c}}=k^{0} e^{-\frac{a F}{R T}\left(E-E^{0 \prime}\right)} \\
& k_{\mathrm{a}}=k^{0} e^{\frac{(1-a) F}{R T}\left(E-E^{0 \prime}\right)}
\end{aligned}
$$

Thus, the current density expression of the Faradaic current during the redox reaction of the immobilised species can be given from Equation (4) as a funtion of the surface coverage of the Ox species $\theta=\frac{\Gamma_{\mathrm{Ox}}}{\Gamma^{0}}$, with $\Gamma_{\mathrm{Ox}}$ the surface coverage of the $\mathrm{E}_{\mathrm{Ox}}$ species

$$
i_{\mathrm{F}}=\Gamma^{0} F k^{0}\left[(1-\theta) e^{\frac{(1-a) F}{R T}\left(E-E^{0 \prime}\right)}-\theta e^{-\frac{a F}{R T}\left(E-E^{0 \prime}\right)}\right]
$$

where $F$ is the Faraday constant and the coverage is found by solving the following differential equation,

$$
\frac{d \theta}{d t}=\frac{i_{\mathrm{F}}}{F}
$$

Assuming a cyclic voltammetry experiment where the potential starts from an initial value $E_{\mathrm{I}}$ and is scanned linearly towards more cathodic potentials against time at a certain scan rate $v$, and the scan is reversed at a time $t_{R}$, the applied potential can be expressed as in Equation (6)

$$
E=E_{\mathrm{I}}-v t_{\mathrm{R}}+v\left|t-t_{\mathrm{R}}\right|
$$

In order to also include capacitance in the problem, we shall assume a contribution to the current, which can be expressed as follows

$$
i_{\mathrm{C}}=C_{\mathrm{dl}} \frac{\mathrm{d} E}{\mathrm{~d} t}
$$


where $C_{\mathrm{dl}}$ is the specific capacitance of the double layer. The total current density, $i$, shall be expressed as a sum of the Faradaic and the capacitance contributions,

$$
i(t)=i_{\mathrm{F}}(t)+C_{\mathrm{dl}}\left(v \frac{t-t_{\mathrm{R}}}{\left|t-t_{\mathrm{R}}\right|}\right)
$$

By solving the problem numerically, the cyclic voltammograms are presented in Figure 2, for different $k^{0}$ values. The other parameteres used for this example are $\Gamma^{0}=5.1 \times 10^{-6} \mathrm{~mol} \mathrm{~m}^{-2}, C_{\mathrm{dl}}=1 \mathrm{~F} \mathrm{~m}^{-2}, E^{0 \prime}=0 \mathrm{~V}, v=0.1 \mathrm{~V} \mathrm{~s}^{-1}$. For the different $k^{0}$ values, the peak separation values are presented in Table 1. From these values, one would expect that based on the peak separation of the experimental results at $0.1 \mathrm{~V} \mathrm{~s}^{-1}$ at $0.029 \mathrm{~V}$, a rough estimation of the $k^{0}$ value should be around $5 \mathrm{~s}^{-1}$.

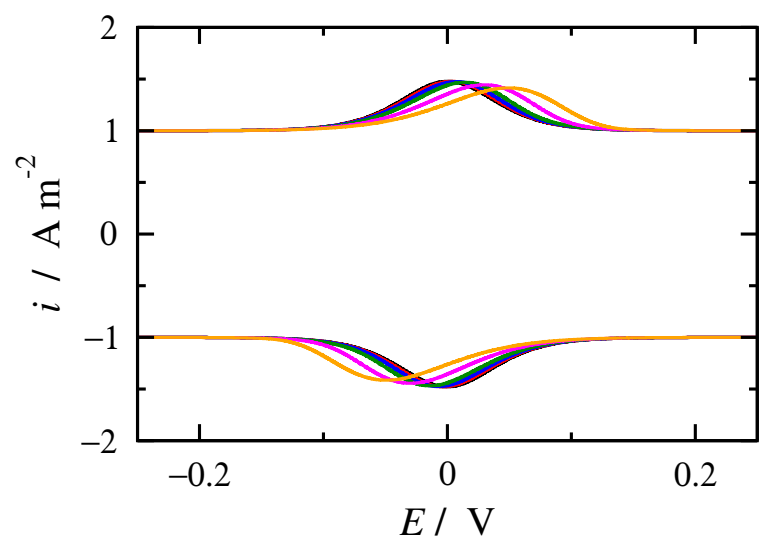

Figure 2. Computational results: Cyclic voltammetry for different $k^{0}$ values. Parameter values: $\Gamma^{0}=5.1 \times 10^{-6} \mathrm{~mol} \mathrm{~m}{ }^{-2}, C_{\mathrm{dl}}=1 \mathrm{~F} \mathrm{~m}^{-2}, E^{0 \prime}=0 \mathrm{~V}, v=0.1 \mathrm{~V} \mathrm{~s}^{-1}$ and $k^{0}=100$ (black), 20 (red), 10 (blue), 5 (green), 2 (orange) and $1 \mathrm{~s}^{-1}$ (orange).

Table 1. Peak separation values for an immobilised species assuming $v=0.1 \mathrm{~V} \mathrm{~s}^{-1}$ and ideal capacitance.

\begin{tabular}{cl}
\hline $\boldsymbol{k}^{\mathbf{0}} / \mathbf{s}^{-\mathbf{1}}$ & $\boldsymbol{\Delta E} / \mathrm{V}$ \\
\hline 100 & 0.000 \\
20 & 0.008 \\
10 & 0.014 \\
5 & 0.026 \\
2 & 0.059 \\
1 & 0.098 \\
\hline
\end{tabular}

\subsection{FT Alternating Current Voltammetry}

Before attempting to extract the $k^{0}, \mathrm{FTacV}$ was performed on a Co-f-MWCNTs modified GC electrode with and without $M t \mathrm{LPMO} 9 \mathrm{H}$. The cathodic 5 th harmonic in acetate buffer $500 \mathrm{mM}, \mathrm{pH} 6$ for $A_{0}=0.2 \mathrm{~V}$ and $f=5$ is presented in Figure 3. In the case of the immobilised enzyme (black curve) a set of intense peaks around the principle peak at $0.25 \mathrm{~V}$. On the other hand, in the absence of the $M t \mathrm{LPMO} 9 \mathrm{H}$, a faint peak of small amplitude appears at $0.2 \mathrm{~V}$ (red curve), leading to the conclusion that the high amplitude harmonic is indeed due to the enzyme and not the immobilization matrix.

Then, FTacV was performed so as to apply the methodology introduced [17] for the extraction of the $k^{0}$. At this point, the methodology is summarized:

1. A harmonic $h$ is chosen, being free of capacitance currents. This harmonic is recorded at a fixed amplitude and decreasing frequencies;

2. The limiting value of the normalized peak height, $I_{\mathrm{p}, h}^{(\mathrm{rev})} / f$, of the principal peak is determined. For this frequency, $f$, the reaction is at the reversible region; 
3. If the transfer coefficient is to be determined, the shift in the potential of the principal peak is plotted as a function of the logarithm of the inverse frequency, $1 / f$. Linear regression is performed in the region of high frequencies and the transfer coefficient is determined;

4. The principal peak height $I_{\mathrm{p}, h}$ of a quasi-reversible harmonic is determined and the value $I_{\mathrm{p}, h} / I_{\mathrm{p}, h}^{(\mathrm{rev})}$ is calculated;

5. The kinetic constant is determined from the graph representing the dependance of $I_{\mathrm{p}, h} / I_{\mathrm{p}, h}^{(\text {rev })}$ on $\log \left(k^{0} / f\right)$.

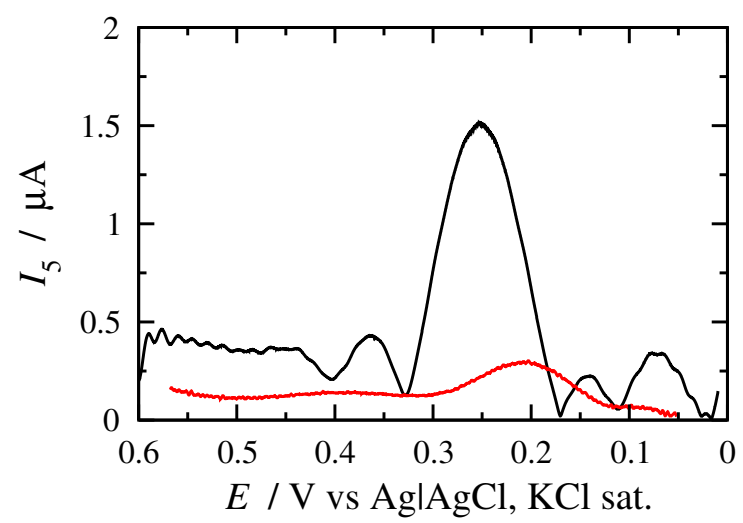

Figure 3. Experimental results: 5th harmonics of MtLPMO9Himmobilised on a Co-f-MWCNTs modified GC electrode (black) and Co-f-MWCNTs modified GC electrode without the enzyme (red) at $25^{\circ} \mathrm{C}$. Experimental conditions: acetate buffer $500 \mathrm{mM}, \mathrm{pH} 6, A_{0}=0.20 \mathrm{~V}$ and $f=5$.

Therefore, as a first step, FTacV was performed for two amplitudes, 0.2 and $0.25 \mathrm{~V}$, at frequencies of 5, 3, 1, 0.5, 0.2 and $0.1 \mathrm{~Hz}$. The scan rate was adjusted at each case accordingly in order to fullfill the slow scan rate approximation and render the experiment independent of this factor $[16,19]$. The cathodic scan of the 4 th and the 5 th harmonics are presented in Figures 4 and 5, respectively, for $A_{0}=0.2$ and $0.25 \mathrm{~V}$. Looking at both the amplitudes employed, there is no intense deformation in the harmonics that would suggest a transfer coefficient that would deviate beyond the range of 0.4-0.6; thus, regarding the dominant peak [17], no significant errors would be inserted in the preliminary analysis in case an $a=0.5$ is assumed. Moreover, both 4 th and 5th harmonic seem free of capacitance contribution.

As a second step, the trend of the main observable, i.e., the peak height of the principle peaks, is to be observed. In both cases, typical 4th and 5th harmonics for quasireversible reactions of immobilised species are presented for the higher applied frequencies (Figures $4 a, c$ and $5 a, c)$. Apparently, as the frequency is decreased, the amplitude of the harmonics decreases, as predicted theoretically. The trend of the normalized peak height of the principle peaks, $I_{\mathrm{p}, h} / f$, on frequency is presented in Figures $4 \mathrm{~b}, \mathrm{~d}$ and $5 \mathrm{~b}, \mathrm{~d}$. By observing these figures, it is evident that a saturation in the peak height of the dominant peak is observed for a frequency of $0.1 \mathrm{~Hz}$. This indicates that reversibility is reached by that point, and the height of the dominant peak of the reversible harmonic, $I_{\mathrm{p}, h}^{(\mathrm{rev})}$ has been determined.

As a next step, a quasi-reversible harmonic is chosen and the ratio $I_{\mathrm{p}, h} / I_{\mathrm{p}, h}^{(\mathrm{rev})}$ is calculated, where $I_{\mathrm{p}, h}$ is the normalised peak current for a quasi-reversible harmonic and $I_{\mathrm{p}, h}^{\text {(rev) }}$ the normalised peak current for the reversible harmonic at a certain $A_{0}$ and $a$. For all the combinations of amplitudes and harmonics, the chosen frequency for the quasi-reversible harmonic is that of $5 \mathrm{~Hz}$, while for the peak of the reversible harmonic, it is $0.1 \mathrm{~Hz}$. Let us now use the example of $I_{\mathrm{p}, 4} / I_{\mathrm{p}, 4}^{(\mathrm{rev})}$ and $I_{\mathrm{p}, 5} / I_{\mathrm{p}, 5}^{(\text {rev })}$ for $0.25 \mathrm{~V}$. The respective estimated values are 0.57 and 0.6 , respectively. 
As a final step, these values shall be used for the estimation of the $k^{0}$ from the nomograms of $I_{\mathrm{p}, h} / I_{\mathrm{p}, h}^{(\mathrm{rev})}$ against the $\log \left(k^{0} f^{-1}\right)$. These nomograms are calculated for $a=0.5$ (Figure $6 \mathrm{a}$ for the 4 th harmonic and Figure $6 \mathrm{~b}$ for the 5 th). The same procedure is done for the amplitude of $A_{0}=0.2 \mathrm{~V}$. By taking an average of the extracted values, the $k^{0}$ is estimated at $4.6 \pm 2.6 \mathrm{~s}^{-1}$.
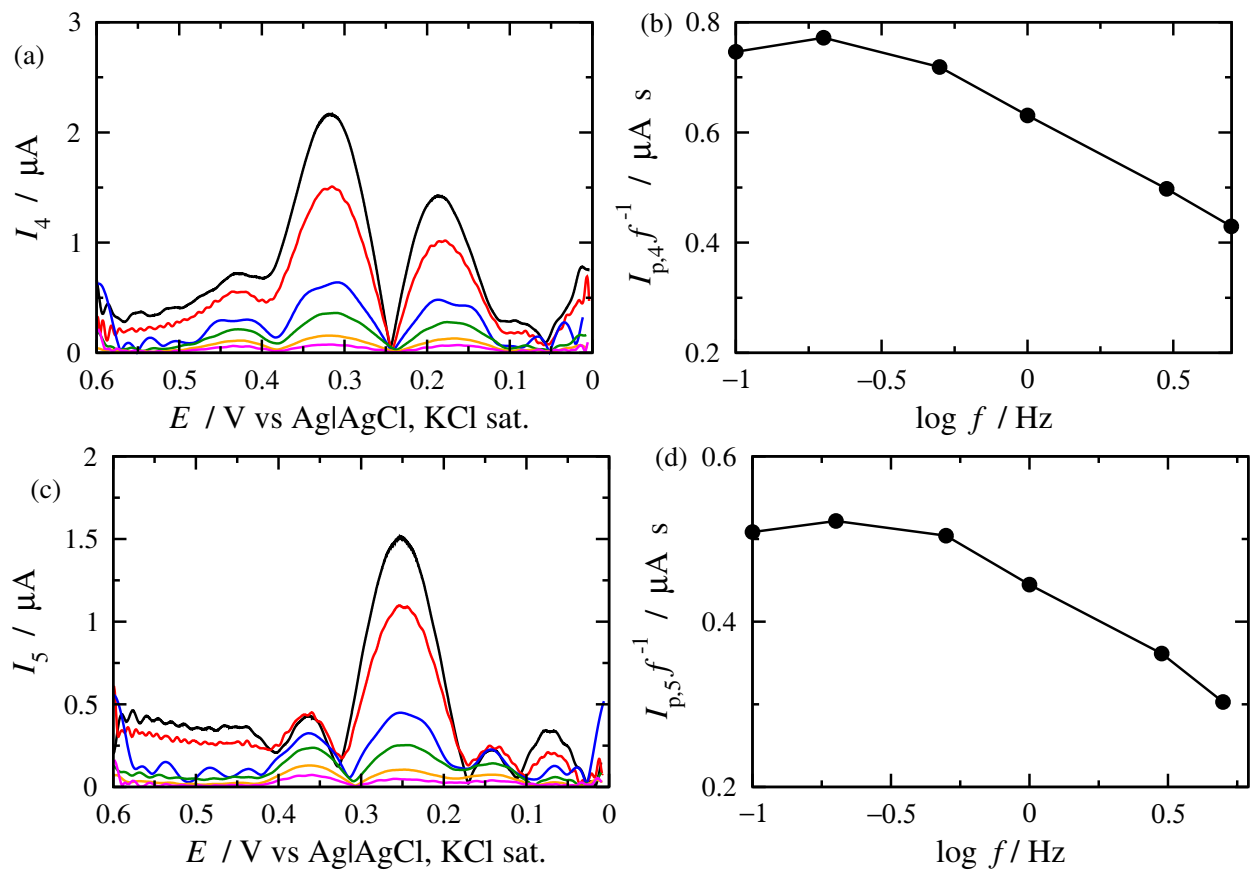

Figure 4. Experimental results: (a) 4th harmonics, (b) normalised peak height of the 4th harmonic, (c) 5th harmonics and (d) normalised peak height of the 5th harmonic, of $M t L P M O 9 H$ immobilised on a Co-f-MWCNTs modified GC electrode at $25^{\circ} \mathrm{C}$. Experimental conditions: acetate buffer $500 \mathrm{mM}$, pH 6, $A_{0}=0.2 \mathrm{~V}$, and $f=5$ (black), 3 (red), 1 (blue), 0.5 (green), 0.2 (orange) and 0.1 (magenta) Hz.
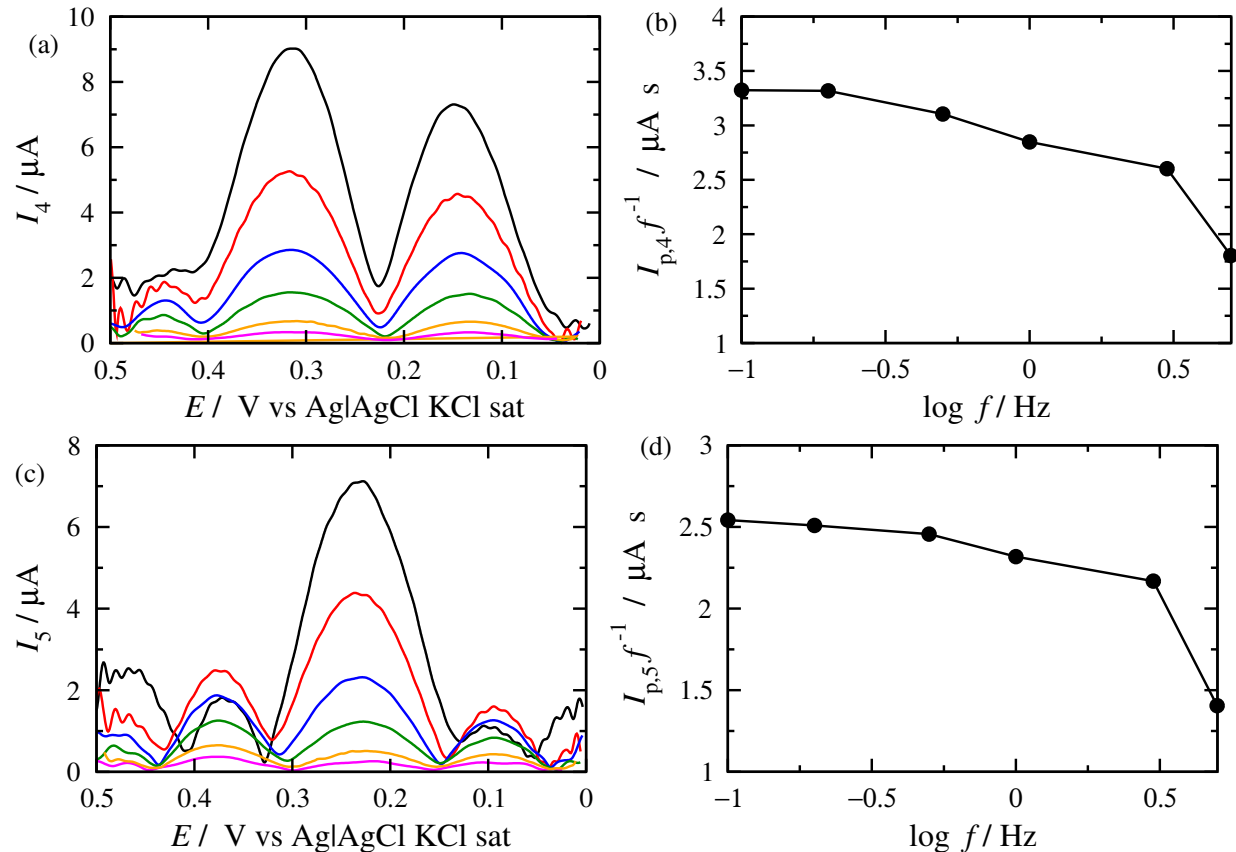

Figure 5. Experimental results: (a) 4th harmonics, (b) normalised peak height of the 4th harmonic, (c) 5th harmonics and (d) normalised peak height of the 5th harmonic, of MtLPMO9H immobilised on a Co-f-MWCNTs modified GC electrode at $25^{\circ} \mathrm{C}$. Experimental conditions: acetate buffer $500 \mathrm{mM}$, $\mathrm{pH} 6, A_{0}=0.25 \mathrm{~V}$, and $f=5$ (black), 3 (red), 1 (blue), 0.5 (green), 0.2 (orange) and 0.1 (magenta) Hz. 


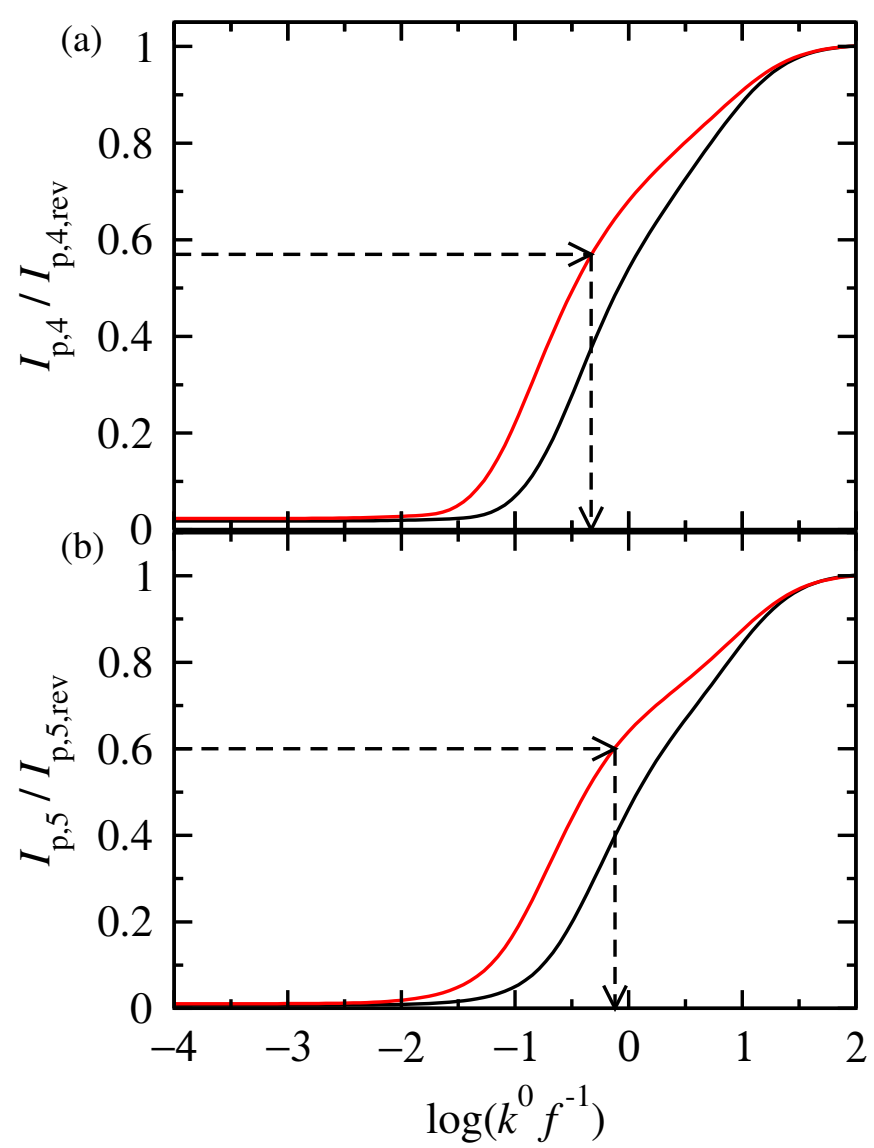

Figure 6. Computational results: Dependence of the normalised principal peak height for the (a) 4th and (b) 5th harmonic of an immobilised species. Parameters: $a=0.5$ and $A_{0}=0.2$ (black) and $0.25 \mathrm{~V}$ (red).

In order to validate the value of $k^{0}$, found experimentally, FTacV experiments were simulated numerically for $k^{0}$ equal to $4.6 \mathrm{~s}^{-1}$ and $a$ equal to 0.57 . In order to do so, Equation (5) was solved numerically where the potential ramp is perturbed by a sinusoidal of amplitude $A_{0}$ and frequency $f$,

$$
E=E_{\mathrm{I}}-v t_{\mathrm{R}}+v\left|t-t_{\mathrm{R}}\right|+A_{0} \sin 2 \pi f t
$$

and the harmonics where calculated from the current obtained by multiplying the current density, Equation (4) with the electrode surface $S$. Apparently, both the surface area $S$ and the surface concentration of the oxidized form of the enzyme $\Gamma^{0}$ are unknown and are expected to vary between different immobilisation experiments. Therefore, the factor $\Gamma^{0} S$ was chosen by trial-and-error. The simulation results (red curves) together with the corresponding experimental plots (black curves) for $A_{0}=0.2, \Gamma^{0} S=3 \times 10^{-13} \mathrm{~mol}$ and $A_{0}=0.25 \mathrm{~V}, \Gamma^{0} S=1.2 \times 10^{-12} \mathrm{~mol}$ and $f=1 \mathrm{~Hz}$, are presented in Figure $7 \mathrm{a}, \mathrm{b}$, respectively. A rather good agreement is observed, implying a satisfactory estimation of $k^{0}$. 

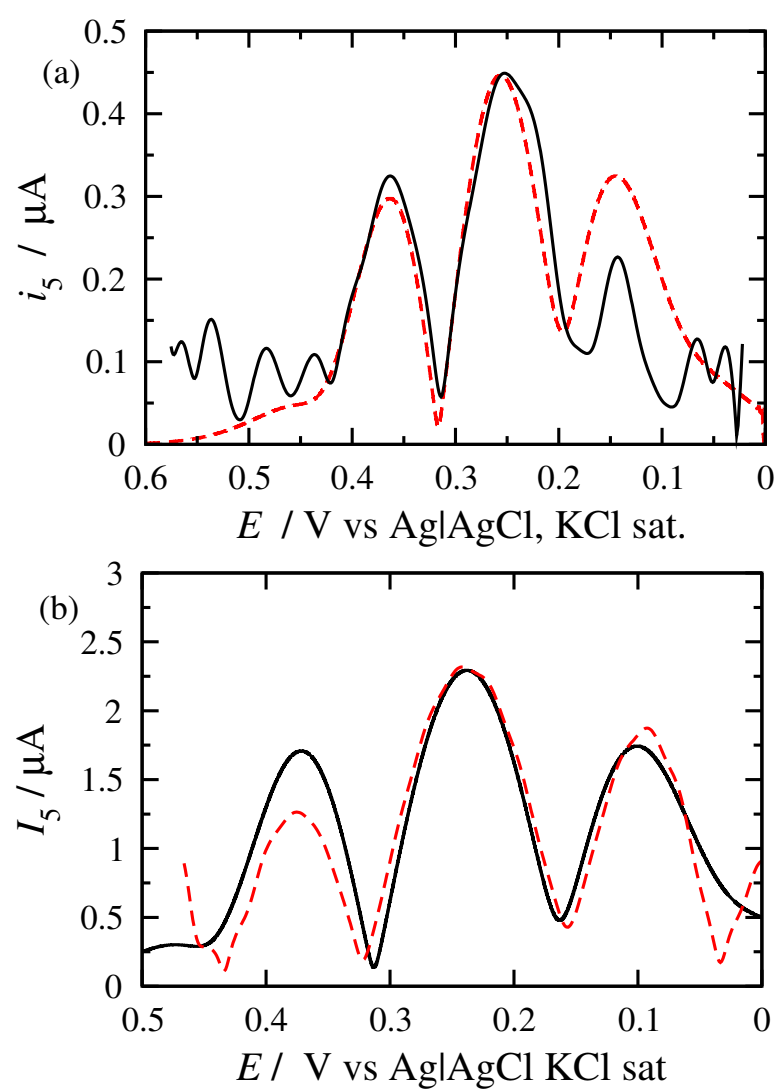

Figure 7. Experimental (black) versus computational (red dashed line) of the 5th harmonic of $\mathrm{MtLPMO} 9 \mathrm{H}$ immobilised on a Co-f-MWCNTs modified GC electrode at $25^{\circ} \mathrm{C}$. Experimental conditions: acetate buffer $500 \mathrm{mM}, \mathrm{pH} 6, f=1 \mathrm{~Hz}$ and (a) $A_{0}=0.2$ and (b) $0.25 \mathrm{~V}$. Computational parameters: a=0.57, $f=1 \mathrm{~Hz}$, (a) $A_{0}=0.2 \mathrm{~V}, \Gamma^{0} S=3 \times 10^{-13} \mathrm{~mol}$ and (b) $A_{0}=0.25 \mathrm{~V}$, $\Gamma^{0} S=1.2 \times 10^{-12} \mathrm{~mol}$.

\section{Discussion}

$M t L P M O 9 H$ was immobilised on an electrode surface, ensuring that direct electron transfer is indeed possible for this enzyme with the immobilisation method used with an indication that, for the conventional scan, rated when using cyclic voltammetry, the kinetics were quasi-reversible. The signal was governed by capacitance, a common feature for immobilised enzymes on electrode surfaces. Despite this, still, an initial estimation of the standard electron transfer rate constant was intented through the computational reproduction of cyclic voltammograms. From the peak separation, it was predicted that the $k^{0}$ would be around $5 \mathrm{~s}^{-1}$, assuming an $a$ equal to 0.5 .

Then FTacV was performed for two different amplitudes as various frequencies in order to assure that both quasi-reversibility and reversibility are achieved in order to apply the methodology to extract the $k^{0}$ of immobilised species using FTacV. The extracted value was at $4.6 \pm 2.6 \mathrm{~s}^{-1}$ being in good accordance with what was expected from cyclic voltammetry.

In order to validate the $k^{0}$ value obtained experimentally, FTacV experiments were simulated numerically and a rather good agreement was found for transfer coefficient $a$ equal to 0.57 . In order to approximate the peak heights of the voltammograms, different values of $\Gamma^{0} S$ were used for the two different amplitudes. At this point, the validity of the $\Gamma^{0} S$ used shall be ascertained. Since the enzyme concentration is $5.5 \mathrm{mg} \mathrm{mL}^{-1}$ and $8 \mu \mathrm{L}$ were utilised, and they were dilluted in $10 \mu \mathrm{L}$ to a final concentration of $4.4 \mathrm{mg} \mathrm{mL}^{-1}$. From this, $2 \mu \mathrm{L}$ were used, and, taking into consideration that the molecular weight of the enzyme is $65 \mathrm{kDa}$ [22], the maximum moles that can be $1.35 \times 10^{-10}$. Considering that not all of the enzymes would be bound to the matrix and from what was bound, not all would be oriented in such a way so as to interact with the enzyme, the values used for 
the simulation seem to be valid. Nevertheless, it has to be pointed out that the proposed experimental methodology for obtaining kinetic parameters does not require knowledge of the surface concentration of the immobilised species or the the value of the surface area.

In general, it is common practice to compare computational with experimental results in order to ascertain the validity of the parameters used for the computational ones. The computational fits tend to reproduce most of the features of the voltammogram, just as in this case, where the basic features of the harmonics presented are fitted rather well $[25,26]$. Regarding the precision of the comparison of the computational harmonics with the experimental ones, it should also be taken into account that the above analysis is valid only if the assumptions of the model are closely met, where the immobilised species must behave as a Langmuirian monolayer and a dispersion of the electrochemical transfer rates should be absent. Otherwise, where kinetic or thermodynamic dispersion is present, more elaborate models have to be considered [27-29]. The influence of kinetic and thermodynamic dispersion might affect the waveform of the voltammograms [30], and other theories such as that of Marcus-Hush can applied, instead of the Butler-Volmer law [31]. Yet, in this case, the Butler-Volmer law seems to be rather sufficient for this case.

To conclude, with the $k^{0}$ value that was estimated, it seems that, under the right conditions, it is feasible to render the system reversible and take advantage of it for bioelectrocatalytic purposes. Thus, it could be proven to be rather resourceful in such applications.

Author Contributions: Conceptualization, D.Z. and A.K. (Antonis Karantonis); methodology, D.Z.; software, A.K. (Antonis Karantonis); validation, D.Z. and A.K. (Antonis Karantonis); formal analysis, R.X., D.Z.; investigation, D.Z.; resources, A.K. (Antonis Karantonis), E.T.; data curation, D.Z.; writingoriginal draft preparation, D.Z., A.K. (Antonis Karantonis); writing-review and editing, A.K. (Antonis Karantonis), A.K. (Anthi Karnaouri), E.T.; supervision, A.K. (Antonis Karantonis), E.T.; project administration, A.K. (Antonis Karantonis); funding acquisition, A.K. (Antonis Karantonis). All authors have read and agreed to the published version of the manuscript.

Funding: The research work was supported by the Hellenic Foundation for Research and Innovation (H.F.R.I.) under the "First Call for H.F.R.I. Research Projects to support Faculty members and Researchers and the procurement of high-cost research equipment grant" (Project Number: HFRI-FM17-3090).

Institutional Review Board Statement: Not applicable.

Informed Consent Statement: Not applicable.

Data Availability Statement: Data sharing not applicable.

Acknowledgments: Chr. Argirusis and P. Pandis are aknowledged for providing the Co-f-MWCNTs.

Conflicts of Interest: The authors declare no conflict of interest.

\section{References}

1. Eibinger, M.; Ganner, T.; Bubner, P.; Rošker, S.; Kracher, D.; Haltrich, D.; Ludwig, R.; Plank, H.; Nidetzky, B. Cellulose surface degradation by a lytic polysaccharide monooxygenase and its effect on cellulase hydrolytic efficiency. J. Biol. Chem. 2014, 289, 35929-35938. [CrossRef] [PubMed]

2. Zhang, R. Functional characterization of cellulose-degrading AA9 lytic polysaccharide monooxygenases and their potential exploitation. Appl. Microbiol. Biotechnol. 2020, 104, 3229-3243. [CrossRef]

3. Moreau, C.; Tapin-Lingua, S.; Grisel, S.; Gimbert, I.; Le Gall, S.; Meyer, V.; Petit-Conil, M.; Berrin, J.-G.; Cathala, B.; Villares, A. Lytic polysaccharide monooxygenases (LPMOs) facilitate cellulose nanofibrils production. Biotechnol. Biofuels 2019, 12, 1-13. [CrossRef]

4. Forsberg, Z.; Stepnov, A.A.; Kruge Nærdal, G.; Klinkenberg, G.; Eijsink, V. G.H. Engineering lytic polysaccharide monooxygenases (LPMOs). Method Enzymol. 2020, 644, 1-34.

5. Hu, J.; Arantes, V.; Pribowo, A; Saddler, J. N. The synergistic action of accessory enzymes enhances the hydrolytic potential of a "cellulase mixture" but is highly substrate specific. Biotechnol. Biofuels 2013, 6, 112. [CrossRef] [PubMed]

6. Zerva, A.; Pentari, C.; Termentzi, A.; America, A.H.P.; Zouraris, D.; Bhattacharya, S.K.; Karantonis, A.; Zervakis, G.I.; Topakas, E. Discovery of two novel laccase-like multicopper oxidases from Pleurotus citrinopileatus and their application in phenolic oligomer synthesis. Biotechnol. Biofuels 2021, 14, 83. [CrossRef] 
7. Frandsen, K.E.H.; Lo Leggio, L. Lytic polysaccharide monooxygenases: A crystallographer's view on a new class of biomassdegrading enzymes. IUCrJ 2016, 3, 448-467. [CrossRef]

8. Bissaro, B.; Røhr, Å.K.; Müller, G.; Chylenski, P.; Skaugen, M.; Forsberg, Z.; Horn, S.J.; Vaaje-Kolstad, G.; Eijsink, V.G.H. Oxidative cleavage of polysaccharides by monocopper enzymes depends on $\mathrm{H}_{2} \mathrm{O}_{2}$. Nat. Chem. Biol. 2017, 13, 1123. [CrossRef]

9. Vaaje-Kolstad, G.; Westereng, B.; Horn, S.J.; Liu, Z.; Zhai, H.; Sørlie, M.; Eijsink, V.G.H. An oxidative enzyme boosting the enzymatic conversion of recalcitrant polysaccharides. Science 2010, 330, 219-222. [CrossRef]

10. Zerva, A.; Pentari, C.; Grisel, S; Berrin, J.-G.; Topakas, E. A new synergistic relationship between xylan-active LPMO and xylobiohydrolase to tackle recalcitrant xylan. Biotechnol. Biofuels 2020, 13, 142. [CrossRef] [PubMed]

11. Cannella, D.; Chia-wen, C.H.; Felby, C.; Jørgensen, H. Production and effect of aldonic acids during enzymatic hydrolysis of lignocellulose at high dry matter content. Biotechnol. Biofuels 2012, 5, 1-10. [CrossRef] [PubMed]

12. Frommhagen, M.; Westphal, A.H.; Van Berkel, W.J.H.; Kabel, M.A. Distinct substrate specificities and electron-donating systems of fungal lytic polysaccharide monooxygenases. Front. Microbiol. 2018, 9, 1080. [CrossRef] [PubMed]

13. Span, E.A.; Marletta, M.A. The framework of polysaccharide monooxygenase structure and chemistry. Curr. Opin. Struct. Biol. 2015, 35, 93-99. [CrossRef]

14. Chen, H.; Dong, F.; Minteer, S.D. The progress and outlook of bioelectrocatalysis for the production of chemicals, fuels and materials. Nat. Catal. 2020, 3, 225-244. [CrossRef]

15. Masa, J.; Schuhmann, W. Electrocatalysis and bioelectrocatalysis-Distinction without a difference. Nano Energy 2016, 29, 466-475. [CrossRef]

16. Zouraris, D.; Karantonis, A. Large amplitude ac voltammetry: Chief observables for a reversible reaction of free electroactive species. J. Electroanal. Chem. 2019, 847, 113245. [CrossRef]

17. Zouraris, D.; Karantonis, A. Determination of kinetic and thermodynamic parameters from large amplitude Fourier transform ac voltammetry of immobilised electroactive species. J. Electroanal. Chem. 2020, 876, 114729. [CrossRef]

18. Engblom, S.O.; Myland, J.C.; Oldham, K.B.; Taylor, A.L. Large amplitude ac voltammetry-A comparison between theory and experiment. Electroanalysis 2001, 13, 626-630. [CrossRef]

19. Bell, C.G.; Anastassiou, C.A.; O’Hare, D.; Parker, K.H.; Siggers, J.H. Large-amplitude ac voltammetry: Theory for reversible redox reactions in the "slow scan limit approximation". EElectrochim. Acta 2011, 56, 6131-6141. [CrossRef]

20. Zouraris, D.; Dimarogona, M.; Karnaouri, A.; Topakas, E.; Karantonis, A. Direct electron transfer of lytic polysaccharide monooxygenases (LPMOs) and determination of their formal potentials by large amplitude Fourier transform alternating current cyclic voltammetry. Bioelectrochemistry 2018, 124, 149-155. [CrossRef]

21. Zouraris, D.; Kiafi, S.; Zerva, A.; Topakas, E.; Karantonis, A. FTacV study of electroactive immobilized enzyme/free substrate reactions: Enzymatic catalysis of epinephrine by a multicopper oxidase from Thermothelomyces thermophila. Bioelectrochemistry 2020, 134, 107538. [CrossRef] [PubMed]

22. Karnaouri, A.; Muraleedharan, M.N.; Dimarogona, M.; Topakas, E.; Rova, U.; Sandgren, M.; Christakopoulos, P. Recombinant expression of thermostable processive MtEG5 endoglucanase and its synergism with MtLPMO from Myceliophthora thermophila during the hydrolysis of lignocellulosic substrates. Biotechnol. Biofuels 2017, 10, 1-17. [CrossRef] [PubMed]

23. Lowry, O.H.; Rosebrough, N.J.; Farr, A.L.; Randall, R.J. Protein measurement with the Folin phenol reagent. J. Biol. Chem. 1951, 193, 265-275. [CrossRef]

24. Savéant, J.-M.; Costentin, C. Elements of Molecular and Biomolecular Electrochemistry: An Electrochemical Approach to Electron Transfer Chemistry, 2nd ed.; John Wiley \& Sons Inc.: Hoboken, NJ, USA, 2019.

25. Zhang, Y.; Simonov, A.N.; Zhang, J.; Bond, A.M. Fourier transformed alternating current voltammetry in electromaterials research: Direct visualisation of important underlying electron transfer processes. Curr. Opin. Electrochem. 2018, 10, 72-81 [CrossRef]

26. Song, P.; Ma, H.; Meng, L.; Wang, Y.; Nguyen, H.V.; Lawrence, N.S.; Fisher, A.C. Fourier transform large amplitude alternating current voltammetry investigations of the split wave phenomenon in electrocatalytic mechanisms. Phys. Chem. Chem. Phys. 2017, 19, 24304-24315. [CrossRef] [PubMed]

27. Léger, C.; Jones, A.K.; Albracht, S.P.J. Armstrong, F.A. Effect of a dispersion of interfacial electron transfer rates on steady state catalytic electron transport in [NiFe]-hydrogenase and other enzymes. J. Phys. Chem. B 2002, 106, 13058-13063. [CrossRef]

28. Robinson, M.; Ounnunkad, K.; Zhang, J.; Gavaghan, D.; Bond, A.M. Models and their limitations in the voltammetric parameterization of the six-electron surface-confined reduction of $\left[\mathrm{PMo}_{12} \mathrm{O}_{40}\right]^{-3}$ at glassy carbon and boron-doped diamond electrodes. ChemElectrochem 2019, 6, 5499-5510. [CrossRef]

29. Rahman, M.A.; Guo, S.-X.; Laurans, M.; Izzet, G.; Proust, A.; Bond, A.M.; Zhang, J. Thermodynamics, electrode kinetics, and mechanistic nuances associated with the voltammetric reduction of dissolved $\left[\mathrm{n}-\mathrm{Bu}_{4} \mathrm{~N}_{4}\left[\mathrm{PW}_{11} \mathrm{O}_{39}\left\{\mathrm{Sn}\left(\mathrm{C}_{6} \mathrm{H}_{4}\right) \mathrm{C} \equiv \mathrm{C}\left(\mathrm{C}_{6} \mathrm{H}_{4}\right)\left(\mathrm{N}_{3} \mathrm{C}_{4} \mathrm{H}_{10}\right)\right\}\right]\right.$ and a surface-confined diazonium derivative. ACS Appl. Energy Mater. 2020, 3, 13991-14006. [CrossRef]

30. Morris, G.P.; Baker, R.E.; Gillow, K.; Davis, J.J.; Gavaghan, D.J.; Bond, A.M. Theoretical analysis of the relative significance of thermodynamic and kinetic dispersion in the dc and ac voltammetry of surface-confined molecules. Langmuir 2015, 31, 4996-5004. [CrossRef]

31. Stevenson, G.P.; Baker, R.E.; Kennedy, G.F.; Bond, A.M.; Gavaghan, D.J.; Gillow, K. Access to enhanced differences in Marcus-Hush and Butler-Volmer electron transfer theories by systematic analysis of higher order AC harmonics. Phys. Chem. Chem. Phys. 2013, 15, 2210-2221. [CrossRef] 